\title{
Sensing Creativity: the role of materials in shoe design
}

\section{Dr Naomi Braithwaite}

\section{drnaomibraithwaite@gmail.com}

Naomi Braithwaite is a Research Fellow in Product Lifetimes at Nottingham Trent University. Her specialist research areas include creativity and the process of shoe design, material culture, fashion and materiality. She has undertaken an MRes in Anthropology at UCL and has a PhD in Material Culture that explored the creative practice of shoe designers. Her current research focuses on developing strategies to shift consumer behavior and attitudes towards a low material future. For more detail visit: drnaomibraithwaite.com.

Keywords: creativity, sensory, material, shoes, designers, craft

\section{Introduction}

The shoe designer as a twentieth century phenomenon represents the bridging divide between design and craft as the designer transferred the process of making shoes to a factory. Classical notions of design present it as a process whereby drawing is prefigured by a concept, often omitting the importance of materials, which through their particular technical, functional and sensorial properties, direct the nature of design (Küchler 2011). Materials such as leathers, suede, snakeskin and other textiles form the aesthetic characteristics of shoes. These materials are significant to creativity, not just in terms of their look, but also in how they influence the designer through their sensual qualities, which both inspires the future design while directing the physicality of the final form. Little is known of how designers physically engage with these materials. Drawing from an ethnography of the creative practice of studio based shoe designers and the author's own experience of learning shoemaking the essay seeks to address this gap by illustrating the significance of materials to the creative process of shoe design.

Observing the creative process of 23 women's shoe designers witnessed their sourcing of different materials, and their engagement with them which involved wrapping them around the shoe last and imagining through the manipulation of the flat surface how it might transform through making into a structured form. Starting first with the look of the material they would engage tacitly, feeling the flat texture and then wrapping and pulling it around the last, manipulating it to resemble a threedimensional shape. The senses were working together, fuelling their creative imagination and it was this that lead to the conceptualisation of design ideas. Materials were seen to be the sources of inspiration and for these designers' creativity was revealed as a craft process that emerged through the interrelationship of the senses (Howes 2011). The observations and practical experiences drawn 
from the ethnography illustrated how flat materials transformed through the craft of making into shoes, thus presenting creativity as a sense driven, material process.

\section{The sensory practice of the shoe designer}

The design studio of Chau Har Lee was a sensory space filled with noisy sewing machines, hand tools, shoe lasts, materials - leathers, suede, different types of heels some made in wood and others plastic and sketches, all surrounded by the distinct aroma of leather. The materials laid out on her workbench were an array of different colours and textures. Chau found that the possibilities of materials to transform from being flat into the voluminous form of a shoe were sources of fascination and inspiration. She would pick up pieces of material and wrap them around her foot as through this particular engagement she imagined what the material could become. From here she would sketch out ideas, cut and stitch the material pieces that would form the body of the shoe and then start the lasting process.

The lasting process involved her pulling the cut and stitched material across the top of the last and hammering it in place underneath with tacks. It appeared to be a methodical process which involved the continued pulling tight of the material across the last using a pair of pliers. Once tight the next piece was hammered in place (figure 1). The skill of lasting came from both feeling and visualising the tautness of the material. It required a skill whereby the hands worked with the body in relationship to the materials and hand tools. It implied a sensory knowledge with the skilled hand as the 'focal point of craft' (Marchand 2012: 263). Through Chau's creative process the boundaries between design and craft were blurred as creativity was shown as an embodied practice, requiring particular gestures and the sensory knowledge of materials and tools.

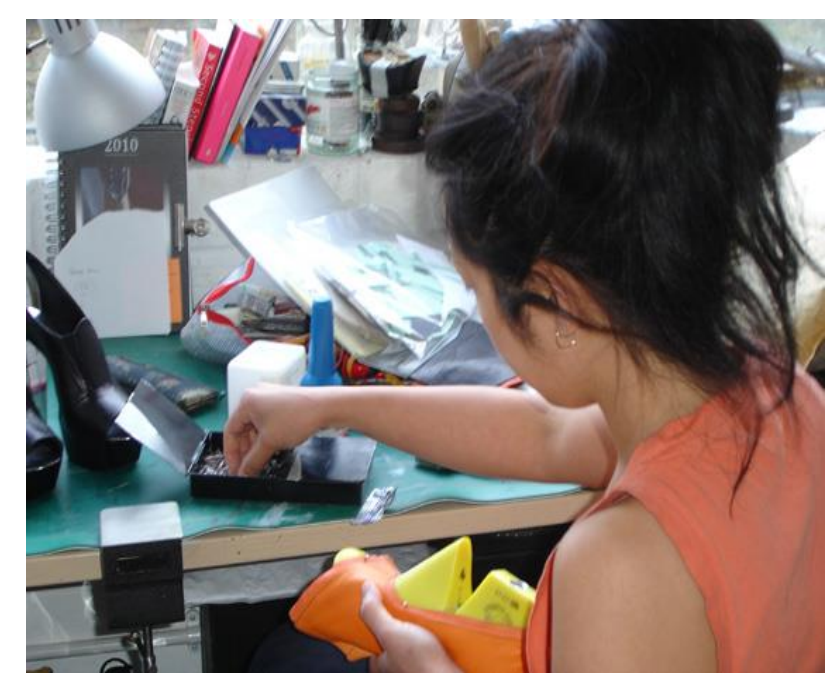

Chau Har Lee - Lasting a shoe design (Cauthor's own photograph) 
The other shoe designers worked in a similar vein, engaging their senses with the different look and textures of materials. Watching these designers select materials and work them into shoes presented shoe design as a craft process that involved particular gestures and motor skills. Sennett presents the ideas of an intelligent hand and how craft therefore requires a tacit knowledge (2008). The work of these shoes designers demonstrated the importance of the hand and touch in acquiring knowledge of the transformative properties of materials. Yet the hand does not work in isolation as particular postures, gestures and responses to the hand tools and materials being worked (Marchand 2012) are needed.

Verbalising their actions and discussing how the process of making happened appeared to be a challenging proposition for these designers. Their actions and subsequent feelings were it seemed beyond verbalization as they worked automatically and did not intentionally think about what they were doing (Bourdieu 1977). How materials transformed through the act of lasting, for example, was tacit and non-verbal (Polanyi 1967). Motor activities can become so automatic that after time they are less open to description (Keller 2001). As the role of the ethnographer is to offer descriptions it seemed pertinent that I found a way to put a voice to these designers' creative and sense driven actions. As Lemmonier suggests a 'little familiarity can help one describe a process' (1992: 28). It seemed that applying a reflective approach whereby I could learn how to make shoes would enable my own understanding and subsequent descriptions of shoe design as a craft, sense driven process. I therefore enrolled on a beginner's shoemaking course, where I would learn to make a pair of shoes by hand.

\section{Coming to shoemaking}

The ethnography identified shoemaking to be defined by particular actions of clickingí, closingii and finally lasting. The first stage was to cut out the different parts of the design pattern from a large gold leather skin. During this process I worked with a cardboard pattern and a sharp, skiving knife. Placing the leather flat I drew carefully around the pattern and then using the knife I slowly cut, endeavoring to follow the marked lines. Using this knife required a particular skill of hand movement, applying pressure whilst moving the knife slowly around the lines of the pattern. Although observations of the shoe designers had shown that cutting material was an embodied practice, I had not considered the significance of posture in this. Correct posture was crucial in the clicking process as you must stand with your weight bearing down on the knife as it moves round and cuts the leather.

The next stage was to learn closing. Stitching was done by sitting at a sewing machine, but what struck me was the importance of control initiated not just by the hand guiding the leather round, but 
also the foot on the pedal that controlled the sewing action. I watched demonstrations of the correct technique and saw how important it was to work slowly doing a couple of stitches at a time. Yet when it came to doing it, nothing prepared me for the speed at which the machine moved and the difficulty of keeping the needle running round a curved seam. The act of stitching utilized the senses and was about feeling the right amount of pressure between foot and the pedal that controlled the stitching. Successful action came through the realization that it was my body that needed to control the movement of the sewing machine and therefore guide the material. .

The next stage was lasting. I had to fix the sole of the shoe onto the bottom of the last. This was done by hammering large tacks through the sole and into the base of the last. As I went to hit the tack it was difficult to gauge the direction and the force at which the nail should be hit. It was an unfamiliar action and took many attempts to get the tacks in place. Once the sole was attached I placed the cut and stitched uppers over the top of the last and secured the back part of the heel area onto the last.

Once fixed in place, the last was placed upside down on top of the lasting peg. Mark, the teacher, demonstrated how the underneath of the last should be held in one hand while the other would use the lasting pincers to pull the lining material over the top of the last. Once the material was taut he pushed a tack into the material and hammered with short, sharp strokes. As he lasted he moved from side to side of the last repeating the same motions. The next stage was to pull the leather tight over the toe and fix it in place with a tack. He started with five tacks, and continued to add tacks from side to side. As he performed the actions he gave sparse descriptions of the process, telling us to just keep pulling the leather until it felt tight.

Hammering the tacks through the material into the last was challenging. As I placed the tack and hit the hammer down, I either bent the tack or dislodged it from the material, meaning that I had to continually repeat the action. During his training as a Navajo silversmith, John Adair recorded that 'hammering always looked very easy....' (Adair 1944:75). As a tool the hammer impinges upon the consciousness of its user. My own impression of observing Mark using the hammer in quick, smooth and successive actions was that it looked incredibly easy. Yet in practice it was hard to pull the leather over the last, keeping it smooth and taut while hammering the tacks into it. As I held the hammer in my hand it felt heavy and awkward and I experienced a sense of deliberation over the hammering action I was about to perform. I was unsure how hard or quickly I should move the hammer and as a consequence I hammered too lightly and the action was unsuccessful. I realized that I was seeing the hammer as distinct from my body (Wynn 1994) and for that reason I was feeling anxious about the act that I was performing (Keller 2001). I needed to reconsider my posture 
standing to the side of the lasting peg and directing the hammer down on a straight line rather than at an angle. With each hit I improved my skill and as I became competent I no longer thought about the action I was performing.

What was most striking about the lasting experience was how it played upon my sensory experience and required the development of a tacit knowledge. As I pulled the leather over the last, I could feel it move through my hands and as I felt for its tautness I was experiencing embodied knowledge, since my hand seemed to be telling me if the shoe was correctly lasted. However, the role of sight was significant here as the hand and hammer was being guided towards the nail by vision (Marchand 2012). Learning these process and doing it by hand, revealed how senses drive creativity and how materials react with form through manual processes. As I witnessed the material transform from a flat state into the volume of a shoe, I realized that what the hand does in relation to flat materials is quite different to what it does in relation to three-dimensional forms. Finally the shoe was made and it stood as a material representation of the tools and the actions that had been performed upon it.

\section{Conclusion}

Through the ethnography and reflective practice it was evident that the creativity of these shoe designers was a craft driven process that played on the interrelationships of the senses (Howes 2011). Through their engagement with materials touch was both proactive and reactive as it triggered knowledge that informed the future designs. As I, and the designers, worked the materials with tools our senses guided us in terms of the particular gestures and hand movements needed (Marchand 2012). The hands worked with the body and its posture responded to the different functional and aesthetic properties of the materials. The ethnography revealed the integral role that materials have to design and creativity and in so doing has shown how these shoe designers engaged in craft practice. The designed shoes emerged through craft as the interrelationships between materials, tools, processes and the bodily consciousness and skills of their creators unified through creative practice. 


\section{Notes}

'Clicking is the cutting of the design pattern out of leather or other material. The term clicking originated because of the sound the knife would make against the brass cutting board which was used in traditional shoemaking factories. In modern factories this cutting out or clicking is done by machines or lasers. In the studios of the profiled designers they still used the traditional clicking method of a skiving knife and wooden or brass topped cutting board.

ii Closing is the stitching together of the cut out pattern pieces which will eventually make up the designed shoe.

\section{References}

Adair, John. 1994. The Navajo and Pueblo Silversmiths. Norman: University of Oklahoma Press. Bourdieu, Pierre. 1977. Outline of a Theory of Practice. Cambridge: Cambridge University Press. Howes, David. 2011. The Craft of the Senses, www.centreforsensorystudies.org/occasionalpapers/the-craft-of-the senses/, accessed on 20 November 2014.

Keller, Charles. 2001. 'Thought and Production: Insights into the Practitioner'. In Michael Schiffer ed. Anthropological Perspectives on Technology. University of Mexico Press.

Küchler, Susanne. 2011. 'Materials and Design'. In Alison J. Clarke ed. Design Anthropology: Object Culture in the $21^{\text {st }}$ Century. New York: SpringerWien.

Lemmonier, Pierre. 1992. Elements for an Anthropology of Technology. The Regents of the University of Michigan.

Marchand, Trevor. 2012. 'Knowledge in Hand: Explorations of Brain, Hand and Tool'. In Richard Fardon et al. eds. The Sage Handbook of Social Anthropology. London: Sage Publications, pp: 261272.

Morris, Robert. 1970. 'Some notes on the Phenomenology of Making: the Search for the Motivated'. In Glenn Adamson ed. The Craft Reader, Oxford, New York: Berg Publishers, pp: 540-547.

Polanyi, Michael. 1967. The Tacit Dimension. London: Routledge.

Reichard, Gladys. 1974. On weaving a Navajo Blanket. New York: Dover Press. 
Sennett, Richard. 2008. The Craftsman. London: Penguin.

Vinken, Barbara. 2005. Fashion Zeitgeist: Trends and Cycle in the Fashion System. Oxford:

Berg Publishers.

Wynn. Thomas. 1994. 'Tools and Tool Behaviour'. In Tim Ingold ed. Companion Encyclopedia of Anthropology. London: Routledge. 